the Total Environment

Elsevier Editorial system(tm) for science of

Manuscript Draft

Manuscript Number:

Title: Kinetic modelling of a diesel-polluted clayey soil bioremediation process

Article Type: Research Paper

Keywords: bioremediation, soil, hydrocarbon, kinetic, modelling

Corresponding Author: Dr. Jose Villaseñor, PhD

Corresponding Author's Institution: University Castilla La Mancha

First Author: Engracia Lacasa Fernández, Ph D

Order of Authors: Engracia Lacasa Fernández, Ph D; Elena Moliterni Merlo, $\mathrm{Ph}$ D; Lourdes Rodríguez Mayor, PhD; Jose Villaseñor, PhD

Abstract: A mathematical model is proposed to describe a diesel-polluted clayey soil bioremediation process. The reaction system under study was considered a completely mixed closed batch reactor, which initially contacted a soil matrix polluted with diesel hydrocarbons, an aqueous liquid-specific culture medium and a microbial inoculation. The model coupled the mass transfer phenomena and the distribution of hydrocarbons among four phases (solid, S; water, A; non-aqueous liquid, NAPL; and air, V) with Monod kinetics. In the first step, the model simulating abiotic conditions was used to estimate only the mass transfer coefficients. In the second step, the model including both mass transfer and biodegradation phenomena was used to estimate the biological kinetic and stoichiometric parameters. In both situations, the model predictions were validated with experimental data that corresponded to previous research by the same authors. A correct fit between the model predictions and the experimental data was observed because the modelling curves captured the major trends for the diesel distribution in each phase. The model parameters were compared to different previously reported values found in the literature. Pearson correlation coefficients were used to show the reproducibility level of the model.

Suggested Reviewers: Jose Joaquín Linares PhD

University of Brasilia

joselinarescunb.br

Enviromental remediation researcher

Francisco García Herruzo PhD

University of Malaga

herruzo@uma.es

Soil remediation researcher

Sam. E. Agarry PhD

Ladoke Atinkola University of Technology

sam agarry@yahoo.com

Soī bioremediation researcher 
Are. Dadrasnia PhD

University of Malasya

are.dadrasnia@gmail.com

Soil bioremediation researcher

Karine Groenen Serrano PhD

Universite Paul Sabatier

serrano@chimie.ups-tlse.fr

Environmental remediation researcher

Opposed Reviewers: 
Science of the Total Environment

Editor
Dr. José Villaseñor Camacho

Chemical Engineering Department, ITQUIMA

University of Castilla - La Mancha

13071 Ciudad Real

SPAIN

\section{Dear Editor:}

Attached you will find the submitted manuscript "Kinetic modelling of a diesel polluted clayey soil bioremediation process" by Engracia Lacasa Fernández, Elena Moliterni Merlo, Lourdes Rodríguez Mayor and José Villaseñor Camacho (corresponding author: jose.villasenor@uclm.es) in order to be reviewed for a possible publication as original research article in S.T.E. (suggested classification: bioremediation).

The work described has not been published previously, in whole or in part, and it is not under consideration for publication elsewhere. All authors are aware of, and accept responsibility for, the manuscript, and they mutually agree that it should be submitted to S.T.E. The manuscript was not previously submitted to S.T.E. and it was revised by a professional English Language editing service.

This is an original work reached out by the authors in the Chemical Engineering Department of the University of Castilla La Mancha (Address for corresponding author: Research Institute for Chemical and Environmental Technology (ITQUIMA). University of Castilla La Mancha, 13071, Ciudad Real, Spain; phone: 34-926295300). Email address:

engracia.lacasa@uclm.es; elenamoliterni@gmail.com; lourdes.rodriguez@cnh2.es; jose.villasenor@uclm.es.

\section{Rationale for relevance to S.T.E.:}

The present work offers valuable and novel information about the mathematical modelling of a complex process such as the bioremediation of hydrocarbon polluted soils. The proposed model tries to couple both transport phenomena, and hydrocarbons distribution among four different phases, with biodegradation phenomena. It has been made an effort to obtain background information about modelling of bioremediation processes, in order to compare with the proposal by the authors. Only few mathematical models that couple mass transfer with Monod or first-order kinetics for hydrocarbon biodegradation are found in the literature. The model predictions have been validated through the comparison with experimental data that had already been reported in the current literature by the same authors.

We consider that the work is directly related to the S.T.E. objectives and it could be classified in the "bioremediation" section. The work has been developed in a laboratory scale following correct scientific methods.

Yours sincerely 
1. Hydrocarbons $(\mathrm{HC})$ polluted soil suspension in water.

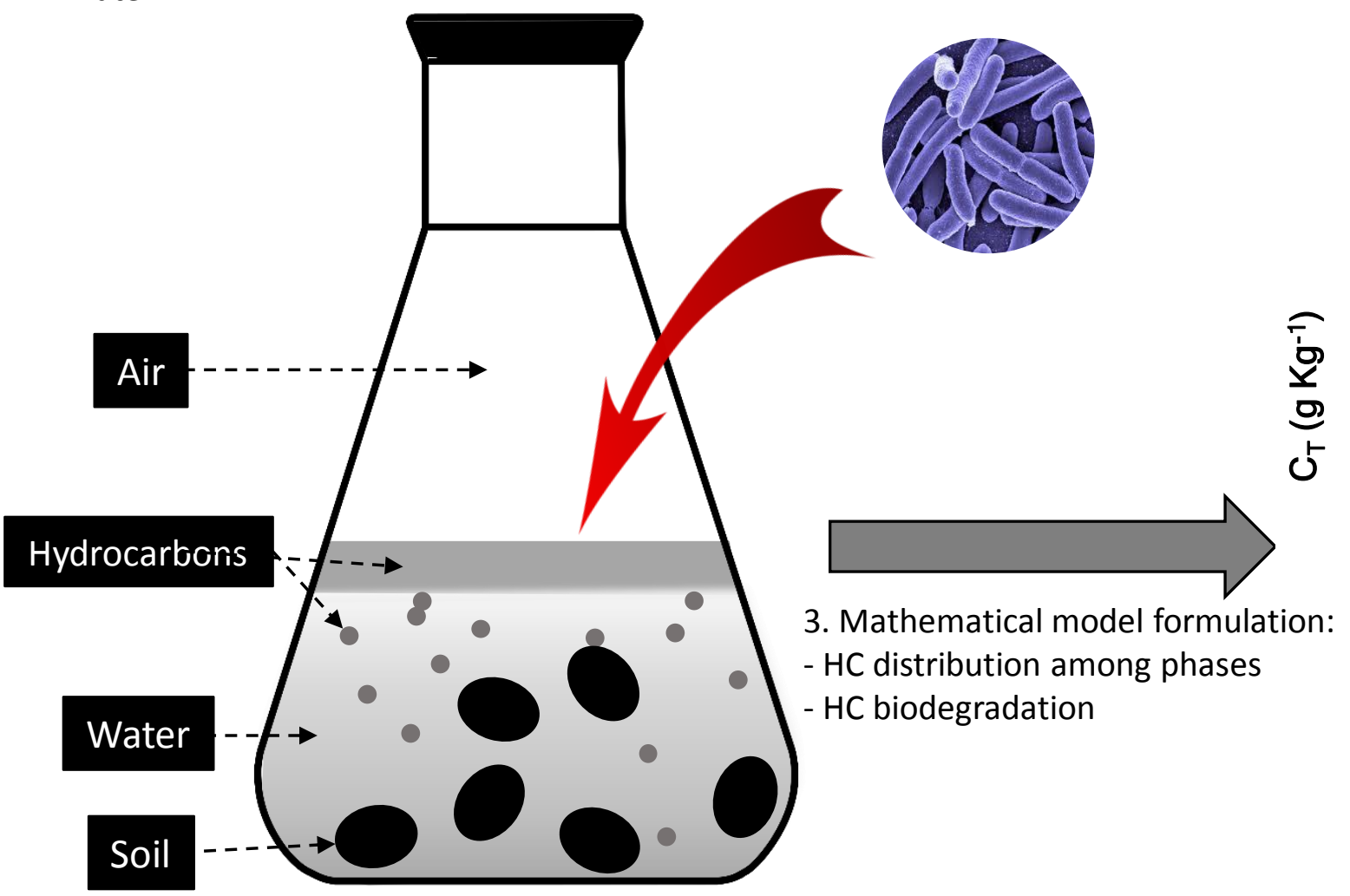

2. Addition of Diesel degrading microorganisms.

4. Model predictions.

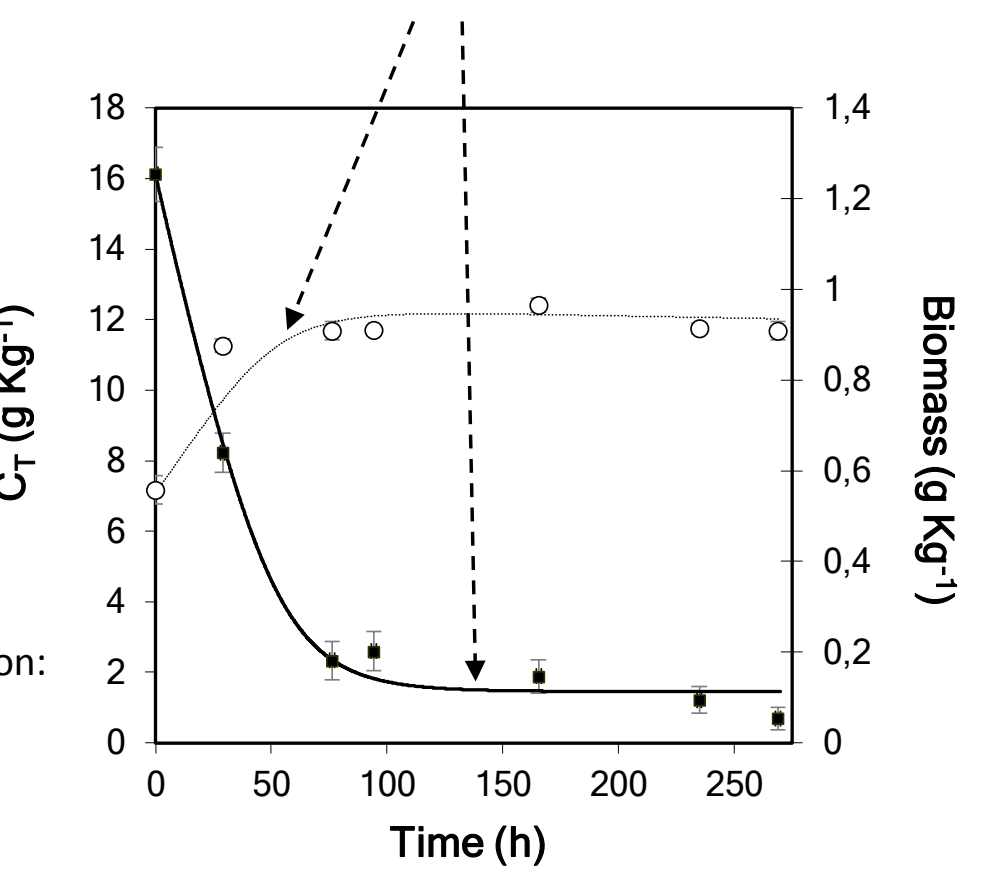


1 A mathematical model is proposed to describe a soil bioremediation process

2 The model couples mass transfer phenomena among phases with biodegradation

3 Model predictions were validated with previous data reported by the authors

4 A correct fit and correlation coefficients were observed 


\title{
Kinetic modelling of a diesel-polluted clayey soil bioremediation process
}

\author{
Engracia Lacasa Fernández ${ }^{1}$, Elena Moliterni Merlo ${ }^{1}$, Lourdes Rodríguez Mayor ${ }^{2}$ and José \\ Villaseñor Camacho ${ }^{1, *}$
}

1 Chemical Engineering Department. Research Institute for Chemical and Environmental Technology (ITQUIMA). University of Castilla La Mancha, 13071, Ciudad Real, Spain.

2 National Institute for Hydrogen Research, C/Fernando el Santo, 13500, Puertollano, Spain

*Corresponding author. Tel.: +34 9262953 00. E-mail: jose.villasenor@uclm.es

\begin{abstract}
A mathematical model is proposed to describe a diesel-polluted clayey soil bioremediation process. The reaction system under study was considered a completely mixed closed batch reactor, which initially contacted a soil matrix polluted with diesel hydrocarbons, an aqueous liquid-specific culture medium and a microbial inoculation. The model coupled the mass transfer phenomena and the distribution of hydrocarbons among four phases (solid, S; water, A; nonaqueous liquid, NAPL; and air, V) with Monod kinetics. In the first step, the model simulating abiotic conditions was used to estimate only the mass transfer coefficients. In the second step, the model including both mass transfer and biodegradation phenomena was used to estimate the biological kinetic and stoichiometric parameters. In both situations, the model predictions were validated with experimental data that corresponded to previous research by the same authors. A correct fit between the model predictions and the experimental data was observed because the modelling curves captured the major trends for the diesel distribution in each phase. The model parameters were compared to different previously reported values found in the literature. Pearson correlation coefficients were used to show the reproducibility level of the model.
\end{abstract}


Keywords: bioremediation; soil; hydrocarbon; kinetic; modelling

\section{Nomenclature}

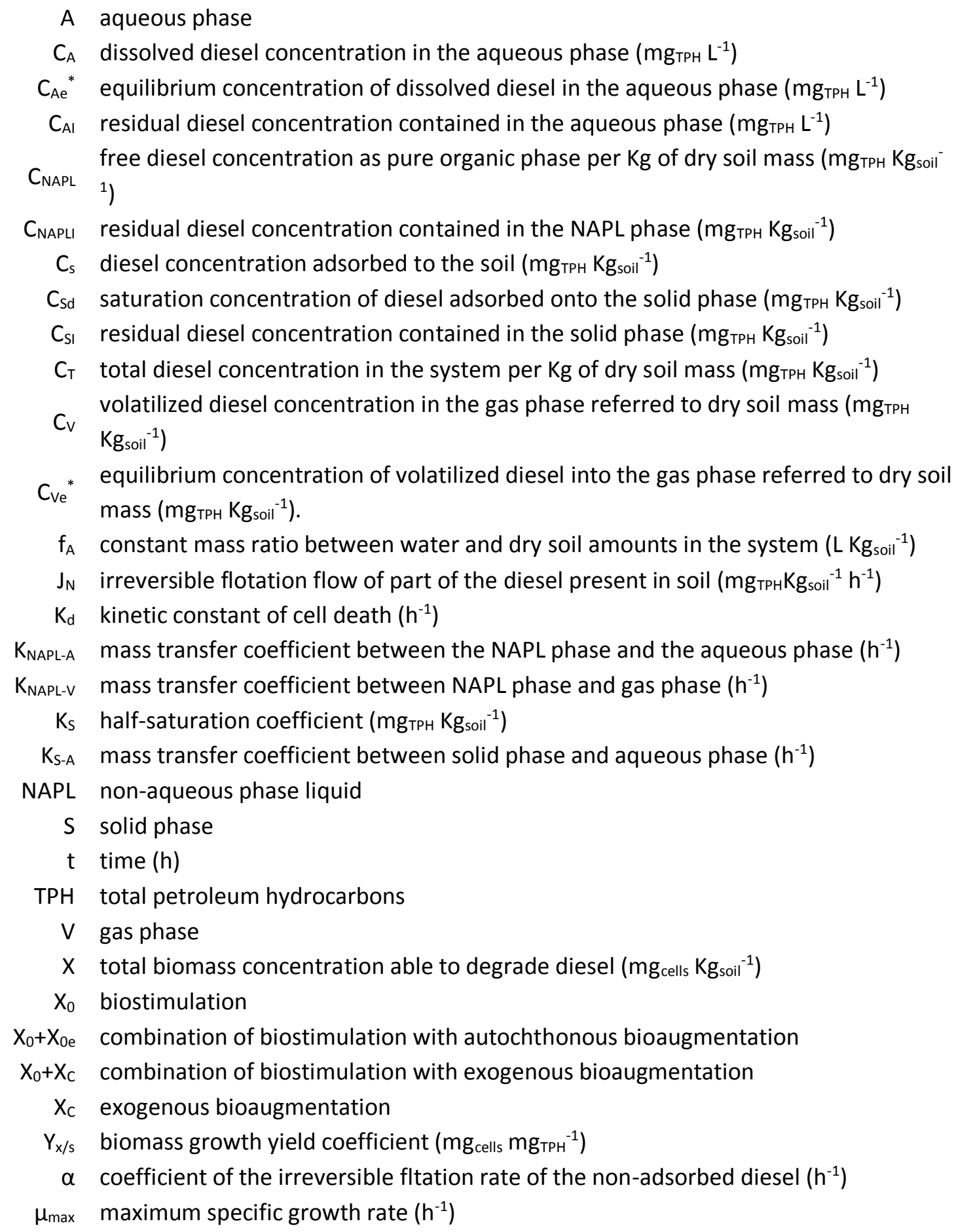

$f_{A}$ constant mass ratio between water and dry soil amounts in the system $\left(\mathrm{L} \mathrm{Kg}_{\mathrm{soil}^{-1}}{ }^{-1}\right)$

$J_{N}$ irreversible flotation flow of part of the diesel present in soil $\left(\mathrm{mg}_{\mathrm{TPH}} \mathrm{Kg}_{\mathrm{soil}^{-1}} \mathrm{~h}^{-1}\right)$

$\mathrm{K}_{d} \quad$ kinetic constant of cell death $\left(\mathrm{h}^{-1}\right)$

$K_{\text {NAPL-A }}$ mass transfer coefficient between the NAPL phase and the aqueous phase $\left(h^{-1}\right)$

$\mathrm{K}_{\text {NAPL-V }}$ mass transfer coefficient between NAPL phase and gas phase $\left(\mathrm{h}^{-1}\right)$

$\mathrm{K}_{S}$ half-saturation coefficient $\left(\mathrm{mg}_{\mathrm{TPH}} \mathrm{Kg}_{\text {soil }}{ }^{-1}\right.$ )

$\mathrm{K}_{\mathrm{S}-\mathrm{A}}$ mass transfer coefficient between solid phase and aqueous phase $\left(\mathrm{h}^{-1}\right)$

NAPL non-aqueous phase liquid

$S$ solid phase

$\mathrm{t}$ time (h)

TPH total petroleum hydrocarbons

$\mathrm{V}$ gas phase

$X$ total biomass concentration able to degrade diesel $\left(\mathrm{mg}_{\text {cells }} \mathrm{Kg}_{\text {soil }}{ }^{-1}\right)$

$\mathrm{X}_{0}$ biostimulation

$\mathrm{X}_{0}+\mathrm{X}_{0 \mathrm{e}}$ combination of biostimulation with autochthonous bioaugmentation

$\mathrm{X}_{0}+\mathrm{X}_{\mathrm{C}}$ combination of biostimulation with exogenous bioaugmentation

$X_{C}$ exogenous bioaugmentation

$\mathrm{Y}_{\mathrm{x} / \mathrm{s}}$ biomass growth yield coefficient $\left(\mathrm{mg}_{\text {cells }} \mathrm{mg}_{\mathrm{TPH}}{ }^{-1}\right)$

$\alpha$ coefficient of the irreversible fltation rate of the non-adsorbed diesel $\left(h^{-1}\right)$

$\mu_{\max }$ maximum specific growth rate $\left(\mathrm{h}^{-1}\right)$ 


\section{Introduction}

Petroleum hydrocarbons are hazardous substances that are released into soils as a consequence of accidental spills in the transport, refining and storage stages. Many alternatives are available for the remediation of hydrocarbon contamination in soils, although bioremediation is one of the most eco-friendly technologies. The efficiency of the bioremediation process for hydrocarbon-polluted soils can be increased using the following methodologies: (1) biostimulation, which involves improving the operating conditions, such as nutrient concentrations, $\mathrm{pH}$ level and moisture content, that affect the bioremediation process and thereby improving the potential of autochthonous microorganisms and (2) bioaugmentation, which is based on inoculation with special microbiota (Gentry et al., 2004). Several possibilities for bioaugmentation exist: a single strain or a known mixed microbial consortium can be used; an autochthonous microbial consortium previously isolated from the polluted soil and cultivated with hydrocarbons as the carbon source can be used, or an exogenous consortia previously drawn from a different hydrocarbon polluted site can be used (Ueno et al., 2007). In the literature, some research papers compare the role of bioaugmentation to the role of biostimulation related to the efficiency of the bioremediation of hydrocarbon-polluted soils (Agarry et al., 2013; Fan et al., 2014).

The bioaugmentation is a promising and low-cost bioremediation technology, and its effectiveness can be influenced by abiotic factors such as $\mathrm{pH}$, temperature, soil properties, chemical structure, concentration and availability of pollutants and by biotic factors such as the selection of the proper microorganisms, competition with indigenous microorganisms or predation by protozoa (Mrozik and Piotrowska-Seget, 2010). Different researchers have studied bioaugmentation processes and reported hydrocarbon removal efficiencies between approximately 70 and 96\% (Gargouri et al., 2014; Ma et al., 2015; Nasseri et al., 2010). Furthermore, other researchers have studied the hydrocarbons biodegradation efficiency in 
soils using a combined biostimulation-bioaugmentation treatments (Agarry and Latinwo, 2015; Fan et al., 2014; Suja et al., 2014).

The authors of the present work previously studied the bioremediation of a diesel-polluted soil with several strategies that combined biostimulation and bioaugmentation through soil-water suspension batch microcosm experiments (Moliterni et al., 2012a). We found that the efficiency of the process strongly depended on the pollutant availability and the soil properties. The pollutant distribution and transport between the different phases in the soil matrix is a very important aspect to be considered. This aspect depends on the physicochemical properties of the soil (Atlas and Bartha, 1998). In soil-water slurry systems, where the hydrocarbon is partially or strongly adsorbed to the soil particles, hydrocarbon accessibility by the microbial population is presumed to be limited. The studies about mass transfer of pollutants between different phases involved in the process must be mentioned: the soil matrix as solid phase (S), water or aqueous (A) and organic (NAPL) as liquid phases, and air in contact with these phases as the gas phase (V) (Hale and Werner, 2010; Mukherji et al., 1998). Likewise, many other reports are based on studies of hydrocarbon desorption (Juhasz et al., 2014; Spasojevic et al., 2015; Wang and Vipulanandan, 2001) and solubility, as well as the use of surfactants (Fan et al., 2014; Lin et al., 2011; Souza et al., 2014). Furthermore, a controversial point is found in the literature concerning the availability of hydrocarbons for microorganisms. Several studies indicate that the dissolution rate from the NAPL phase determines the biodegradation rate (Alshafie and Ghoshal, 2003; Ghoshal and Luthy, 1998), because microorganisms are not able to directly consume hydrocarbons from this phase (Mukherji et al., 1998). However, other studies have proposed that microorganisms can directly access hydrocarbons in the organic-water interphase (Nakahara et al., 1977; Rosenberg et al., 1989), which led us to understand the high biodegradation rate of many hydrocarbons in the NAPL phase. 
Modelling of the bioremediation process is a very important tool for reactor design and efficiency prediction. Several mathematical models have been developed and published in the literature to describe the hydrocarbon bioremediation process. Some models are based on the premise that microorganisms can use only the hydrocarbons from the dissolved aqueous phase (Johnson et al., 2013; Mulder et al., 2001; Ostendorf et al., 2007; Ramaswami and Luthy, 1997; Song et al., 2014; Wang and Vipulanandan, 2001), although other models suggest that adsorbed compounds are also directly available for microorganisms without the need to desorb them (Mukherji et al., 1998; Park et ak., 2001; Woo et al., 2001).

Only few mathematical models that couple mass transfer with Monod or first-order kinetics for hydrocarbon biodegradation are found in the literature (Kosterin and Sofinskaya, 2010; Park et al., 2001; Wang and Vipulanandan, 2001; Woo et al., 2001;), and those models were validated for just one or two bioremediation methodologies; there is no concern about mass transfer of hydrocarbon between NAPL and the gas phases in those models.

Thus, in this context, the objective of this study is to propose a mathematical model that describes a diesel-polluted clayey soil bioremediation process. The model couples mass transfer and distribution of diesel hydrocarbons between four phases (S, A, NAPL and V), with Monod kinetics for the biodegradation process. The model predictions have been validated through the comparison with experimental data that had already been reported in the current literature by the same authors (Moliterni et al., 2012a).

\section{Materials and methods}

\subsection{Experimental data}

Experimental data are used in the present work to validate the proposed model. These data correspond to previous research by the same authors, whose objective was to study different biostimulation-bioaugmentation options to remove diesel from clayey and silty polluted soils 
through batch soil-water slurry experiments. The complete description of the experimental procedure was reported by Moliterni et al. (2012a), and only some important details are described here: The clayey soil used in this study was obtained from an agricultural area in Ciudad Real, Spain, and it contained approximately $10^{8}$ and $10^{6} \mathrm{MPN} \mathrm{g}^{-1}$ of total heterotrophic bacteria (THB) and total diesel-degrading bacteria (DDB), respectively. The soil was artificially contaminated with commercial diesel from a petrol station to produce a final concentration corresponding to $17,000 \mathrm{mg} \mathrm{kg}^{-1}$ soil. The autochthonous DDB microbial consortium (named as $\left.X_{0}\right)$ found in the soil was isolated and enriched with diesel fuel for 4 weeks, obtaining an enriched consortium named as $\mathrm{X}_{0 \mathrm{e}}$. In addition, a previously developed microbial consortium isolated from a hydrocarbon-polluted site at an oil refinery in central Spain and enriched in diesel for 4 months was used as the exogenous consortium $\left(X_{C}\right)$ (Moliterni et al., 2012b). Five slurry-phase batch experiments in closed reactors were conducted with clayey soil to evaluate the efficiency of hydrocarbon biodegradation. The experiments were planned to compare the biostimulation and bioaugmentation options, with either the autochthonous consortium, $\mathrm{X}_{0}$, or the exogenous consortium, $X_{c}$. The experimental conditions included a mixing rate of $130 \mathrm{rpm}$, a temperature of $25^{\circ} \mathrm{C}$ and an experimental period of 11 days. To monitor abiotic losses, abiotic control experiments were performed with soils that were autoclaved to inhibit the activity of autochthonous soil microorganisms. The total petroleum hydrocarbon (TPH) concentration in the samples at different retention times was measured by gas chromatography (ISO method 9377-2, 2000; EN method 14039, 2005). The biomass concentration was measured by the most probable number (MPN) method (Youssef et al., 2010). The MPN results were converted to dry cell weights (ASTM E method 1755-01, 1991) using a prepared calibration curve.

\subsection{System description and mathematical model assumptions}

The reaction system under study can be considered a completely mixed batch reactor, which initially contacts a soil matrix polluted with diesel hydrocarbons (organic substrate) and an 
aqueous liquid-specific culture medium (water with inorganic nutrients). Once the solid and water phases have been mixed, a portion of the diesel fuel is transferred from the soil (S) to water (A) and air (V), in addition to as a pure hydrocarbon phase (NAPL), and the system progresses until an equilibrium in the diesel fuel distribution is reached. The reaction starts with the addition and activation of an inoculum from a microbial consortium, which is homogeneously distributed in the medium to reach the initial concentration. Once the reaction has been initiated, the microbial activity consumes hydrocarbons and modifies the equilibrium distribution, and the substrate concentration changes over time due to the transport phenomena between phases and biodegradation. This biodegradation leads to biomass growth.

The following assumptions have been considered to develop the mathematical model:

- The system is assumed to be closed, and the total mass is maintained constant.

- The diesel hydrocarbons are assumed to be present in the system in four phases: dissolved in aqueous phase (A), adsorbed in the soil (S), free in the organic liquid phase (NAPL) or volatilized in the gas phase $(\mathrm{V})$.

- After the inoculation, microorganisms are homogeneously distributed all over the aqueous phase and also have access to hydrocarbons in the following 3 phases: A, S or NAPL. Biodegradation in the $S$ and NAPL phases is assumed to be carried out through A-S and A-NAPL interphases (Guo et al., 1999; Park et al., 2001; Woo et al., 2001) and because of biosurfactant generation (Souza et al., 2014; Suja et al., 2014).

- The microbial consortium responsible for hydrocarbon biodegradation follow growth kinetics according to the Monod equation. For that reason, the system imposes the requirement that the growth rate is null only when the diesel concentration is zero. The existence of a residual substrate concentration in each phase unavailable for growth, even using long incubation time, is considered (Nocentini et al., 2000). This residual concentration can be a non-biodegradable 
fraction or a non-accessible fraction. Thus, the biological reaction is paralysed when the residual concentration is reached.

- During the experiments, hydrocarbon transport phenomena exist among different phases. Because of the practical point of view, the mass transport is considered to be carried out only among some phases due to the system characteristics and the difference between water and NAPL densities (Figure 1). Under the mixing rate applied, the NAPL phase floats and remains above the $A$ phase, and the transport processes between $S-V$ and $A-V$ phases are assumed to be negligible, and these equilibria have therefore not been included in this model approach. The interaction in the S-NAPL phase is not considered as equilibrium, and it is just considered that the excess of diesel oil is separated from soil and moves up by flotation due to its lower density in comparison with water.

\subsection{Model formulation}

A global mass balance of organic substrate (diesel hydrocarbons) is applied in the system. The time variation of the total substrate concentration is the result of the variation in all phases due to transport phenomena and biodegradation. This overall mass balance is shown in Equation [1].

$$
\frac{d C_{T}}{d t}=\frac{d C_{S}}{d t}+f_{A} \cdot \frac{d C_{A}}{d t}+\frac{d C_{N A P L}}{d t}+\frac{d C_{V}}{d t}
$$

where $C_{T}$ is the total diesel concentration in the system per $\mathrm{Kg}$ of dry soil mass $\left(\mathrm{mg}_{\mathrm{TPH}} \mathrm{Kg}_{\mathrm{Soil}}{ }^{-1}\right), \mathrm{C}_{\mathrm{s}}$ is the diesel concentration adsorbed in the soil $\left(\mathrm{mg}_{\mathrm{TPH}} \mathrm{Kg}_{\text {soil }}{ }^{-1}\right), f_{A}$ is the constant mass ratio between water and dry soil amounts in the system $\left(\mathrm{L} \mathrm{Kg}_{\text {soil }}{ }^{-1}\right), \mathrm{C}_{\mathrm{A}}$ is the dissolved diesel concentration in the aqueous phase $\left(\mathrm{mg}_{\mathrm{TPH}} \mathrm{L}^{-1}\right), \mathrm{C}_{\mathrm{NAPL}}$ is the free diesel concentration as pure organic phase per Kg of dry soil mass $\left(\mathrm{mg}_{\mathrm{TPH}} \mathrm{Kg}_{\mathrm{Soil}}{ }^{-1}\right), \mathrm{C}_{\mathrm{V}}$ is the volatilized diesel concentration in 
the gas phase per $\mathrm{Kg}$ of dry soil mass $\left(\mathrm{mg}_{\mathrm{TPH}} \mathrm{Kg}_{\mathrm{Soil}}{ }^{-1}\right)$, and $\mathrm{t}$ is time (h). If no biodegradation exists, $\mathrm{C}_{\mathrm{T}}$ is constant, and equation [1] is equal to zero.

Next, partial diesel mass balances are proposed in each phase of the soil-slurry system: solid, aqueous liquid, gas and NAPL liquid phases. Equation [2] describes the diesel balance in the solid phase. The first two terms on the right side are related to the diesel transport phenomena, whereas the last term corresponds to the diesel biological consumption according to Monod kinetics:

$\frac{d C_{S}}{d t}=J_{n}-f_{A} \cdot K_{S-A} \cdot\left(C_{A e}^{*}-C_{A}\right)-\frac{\mu_{\max } \cdot\left(C_{S}-C_{S I}\right)}{K_{S}+C_{S}-C_{S I}} \cdot X \cdot \frac{1}{Y_{x / s}}$

where $\mathrm{K}_{\mathrm{s}-\mathrm{A}}$ is the mass transfer coefficient between the solid phase and the aqueous phase $\left(\mathrm{h}^{-1}\right)$, $\mathrm{C}_{\mathrm{Ae}}{ }^{*}$ is the equilibrium concentration of dissolved diesel in the aqueous phase $\left(\mathrm{mg}_{\mathrm{TPH}} \mathrm{L}^{-1}\right), \mu_{\max }$ is the maximum specific growth rate $\left(\mathrm{h}^{-1}\right), \mathrm{K}_{\mathrm{s}}$ is the half-saturation coefficient $\left(\mathrm{mg}_{\mathrm{TPH}} \mathrm{Kg}_{\text {soil }}{ }^{-1}\right), \mathrm{X}$ is the total biomass concentration that is able to degrade diesel in the system $\left(\mathrm{mg}_{\text {cells }} \mathrm{Kg}_{\text {soil }}{ }^{-1}\right), \mathrm{Y}_{\mathrm{x} / \mathrm{s}}$ is the biomass growth yield coefficient $\left(\mathrm{mg}_{\text {cells }} \mathrm{mg}_{\mathrm{TPH}}{ }^{-1}\right), \mathrm{C}_{\mathrm{SI}}$ is the residual diesel concentration contained in the solid phase $\left(\mathrm{mg}_{\mathrm{TPH}} \mathrm{Kg}_{\text {soil }}{ }^{-1}\right)$, and finally, $J_{N}$ is the irreversible flotation flow of part of the diesel present in soil $\left(\mathrm{mg}_{\mathrm{TPH}} \mathrm{kg}_{\mathrm{Soil}}{ }^{-1} \mathrm{~h}^{-1}\right)$. This fraction of diesel is desorbed from the soil when the soil is suspended with water, and diesel rises to the top of the soil-slurry system due to its lower density. The $J_{N}$ value has been calculated through equation [3], where $\alpha$ is a coefficient of the irreversible migration rate of the non-adsorbed diesel $\left(h^{-1}\right)$, and $C_{s d}$ is the saturation concentration of diesel adsorbed onto the solid phase $\left(\mathrm{mg}_{\mathrm{TPH}} \mathrm{Kg}_{\mathrm{Soil}}{ }^{-1}\right)$.

$$
J_{n}=\alpha \cdot\left(C_{S d}-C_{S}\right)
$$

Equation [4] describes the diesel balance in the liquid aqueous phase. As in equation [2], the first two terms on the right side are related to the diesel transport phenomena, whereas the last term corresponds to the diesel biological consumption according to Monod kinetics: 
$\frac{d C_{A}}{d t}=K_{S-A} \cdot\left(C_{A e}^{*}-C_{A}\right)+K_{N A P L-A} \cdot\left(C_{A e}^{*}-C_{A}\right)-\frac{\mu_{\max } \cdot\left(C_{A}-C_{A I}\right)}{K_{S} / f_{A}+C_{A}-C_{A I}} \cdot X \cdot \frac{1}{Y_{x / s}}$

where $\mathrm{K}_{\text {NAPL-A }}$ is the is the mass transfer coefficient between the NAPL phase and the aqueous phase $\left(\mathrm{h}^{-1}\right)$, and $\mathrm{C}_{\mathrm{Al}}$ is the residual diesel concentration that is contained in the aqueous phase $\left(\mathrm{mg}_{\mathrm{TPH}} \mathrm{L}^{-1}\right)$.

In the case of the NAPL phase, the partial diesel balance is described in Equation [5], where $\mathrm{C}_{\text {NAPLI }}$ is the residual diesel concentration contained in the NAPL phase $\left(\mathrm{mg}_{\mathrm{TPH}} \mathrm{Kg}_{\mathrm{Soil}}{ }^{-1}\right)$.

$$
\frac{d C_{N A P L}}{d t}=-J_{N}-K_{N A P L-V} \cdot\left(C_{V e}^{*}-C_{V}\right)-f_{A} \cdot K_{N A P L-A} \cdot\left(C_{A e}^{*}-C_{A}\right)-\frac{\mu_{\max } \cdot\left(C_{N A P L}-C_{N A P L}\right)}{K_{S}+C_{N A P L}-C_{N A P L}} X \cdot \frac{1}{Y_{x / s}}
$$

where $\mathrm{K}_{\text {NAPL-V }}$ is the is the mass transfer coefficient between the NAPL phase and gas phase $\left(\mathrm{h}^{-1}\right)$, and $\mathrm{C}_{\mathrm{ve}}{ }^{*}$ is the equilibrium concentration of volatilized diesel onto the gas phase referred to the dry soil mass $\left(\mathrm{mg}_{\mathrm{TPH}} \mathrm{Kg}_{\mathrm{soil}}{ }^{-1}\right)$.

In the case of the gas phase, biological reaction does not occur because microorganisms do not exist, then the partial diesel balance is then defined in Equation [6]:

$$
\frac{d C_{V}}{d t}=K_{N A P L-V} \cdot\left(C_{V e}^{*}-C_{V}\right)
$$

Finally, the global balance of biomass generated in the system is described in Equation [7]. This balance describes the biomass growth due to the diesel consumption in each phase (solid, aqueous and NAPL) and the subtraction of the possible biomass decrease due to cell death processes:

$\frac{d X}{d t}=\frac{\mu_{\max } \cdot\left(C_{A}-C_{A I}\right)}{K_{S} / f_{A}+C_{A}-C_{A I}} \cdot X+\frac{\mu_{\max } \cdot\left(C_{S}-C_{S I}\right)}{K_{S}+C_{S}-C_{S I}} X+\frac{\mu_{\max } \cdot\left(C_{N A P L}-C_{N A P L}\right)}{K_{S}+C_{N A P L}-C_{N A P L}} \cdot X-K_{d} \cdot X$

where $K_{d}$ is the kinetic constant of cell death $\left(h^{-1}\right)$. 
The overall model considers a unique heterotrophic biomass concentration $(X)$ in the soil-slurry system that is able to degrade diesel in whatever phase diesel may be accessible for microorganisms: dissolved diesel (aqueous phase), adsorbed diesel (soil-water interphase) or free diesel (NAPL-water interphase). Regardless of where the diesel substrate is located, the model considers constant values for $\mu_{\max }, \mathrm{Y}_{\mathrm{x} / \mathrm{s}}$ and $\mathrm{K}_{\mathrm{s}}$.

\subsection{Parameter estimation}

\subsubsection{Mass transfer coefficients}

The experimental data obtained under abiotic conditions (no inoculum and autoclaved soil) reported by Moliterni et al. (2012a) allowed us in the present work to obtain the mass transfer coefficients. Obviously, the biodegradation rate term in the equations previously described is zero under abiotic conditions. Here, the result is a four-equation system ([2], [4], [5] and [6]) with four adjustable parameters: $\alpha, K_{S-A}, K_{\text {NAPL-A }}$ and $K_{\text {NAPL-V. }}$. Note that the diesel equilibrium concentrations in the different phases were not obtained by mathematical fitting, but were measured by experimentation in that previous work. This equations system has been fitted to the experimental data obtained under abiotic conditions by using the Gauss-Newton algorithm. An initial value was assigned to the adjustable parameters ( $\left.\alpha, \mathrm{K}_{\mathrm{S}-\mathrm{A}}, \mathrm{K}_{\text {NAPL-A }}, \mathrm{K}_{\text {NAPL-V }}\right)$, and after several iterations, the values of parameters that produced the minimum at the objective function $\Psi(p)$ (Equation [8]) were chosen.

$$
\Psi(p)=\sum_{i=1}^{n}\left(\left(C_{A \exp , i}-C_{A i}(p)\right)^{2}+\left(C_{S \exp , i}-C_{S i}(p)\right)^{2}+\left(C_{N A P L \exp , i}-C_{N A P L i}(p)\right)^{2}+\left(C_{V \exp , i}-C_{V i}(p)\right)^{2}\right)
$$

where $\mathrm{n}$ is the number of experimental data; $\mathrm{C}_{\mathrm{Aexp}, \mathrm{i}}, \mathrm{C}_{\mathrm{Sexp}, \mathrm{i}}, \mathrm{C}_{\mathrm{NAPLexp}, \mathrm{i}}, \mathrm{C}_{\mathrm{Vexp}, \mathrm{i}}$ are the experimental values of diesel concentration in the aqueous liquid, solid, NAPL and gas phases, respectively, when those values were measured at the same $t_{i}$ time; $C_{A i}(p), C_{S i}(p), C_{\text {NAPLi }}(p)$ and $C_{V i}(p)$ are the predicted values calculated by the model, which correspond to $t_{i}$. 


\subsubsection{Kinetic parameters}

Once mass transfer coefficients have been determined by fitting experimental data under abiotic conditions, the stoichiometric and kinetic parameters for the diesel biodegradation were determined by using equations [2], [4], [5] and [7], which were fitted to the experimental data reported by Moliterni et al. (2012a) when both mass transfer phenomena and biological reactions occurred. In this occasion note that the final residual concentrations $\left(C_{S I}, C_{N A P L I}, C_{A I}\right)$ were measured by experimentation in that previous work. The four adjustable parameters $\left(\mu_{\max }\right.$, $\mathrm{K}_{\mathrm{s}}, \mathrm{Y}_{\mathrm{x} / \mathrm{s}}$ and $\mathrm{K}_{\mathrm{d}}$ ) were estimated again using a nonlinear regression technique, minimizing the objective function $\Omega(p)$ (equation [9]), during the simultaneous resolution of equations [2], [4], [5] and [7] by the Gauss-Newton algorithm.

$$
\Omega(p)=\sum_{i=1}^{n}\left(\left(X_{\mathrm{exp}, i}-X_{i}(p)\right)^{2}+\left(C_{\mathrm{exp}, i}-C_{i}(p)\right)^{2}\right)
$$

where $\mathrm{n}$ is the number of pieces of experimental data; $\mathrm{X}_{\text {exp,i }}$ and $C_{\text {exp,i }}$ are the experimental values of biomass and diesel concentrations, respectively, in the aqueous liquid phase, solid, NAPL and gas phases when those values were measured at the same $t_{i}$ time; and $X_{i}(p)$ and $C_{i}(p)$ are the predicted values calculated by the model, which correspond to $t_{i}$.

\section{Results and discussion}

\subsection{Model validation and parameter estimation for abiotic experiments}

Figure 2 shows the diesel distribution (expressed as TPH) among the four phases (S, A, NAPL, and V) considered in the system under abiotic conditions (i.e., no biodegradation is present). Points correspond to experimental data, while lines correspond to the model predictions. The clayey soil quickly transferred part of the diesel into the liquid phase (aqueous and NAPL phases); approximately $55 \%$ of the diesel was detected in the liquid phase after the first $48 \mathrm{~h}$, although approximately $40 \%$ of the diesel was not desorbed from the clayey soil at the end of the 
experiments. A correct fit between the model predictions and the experimental data can be observed because the modelling curves capture the major trends for the diesel distribution in each phase.

Moreover, Figure 3 represents the TPH concentration calculated as the sum of TPH in the three phases ( $\mathrm{S}, \mathrm{A}$ and NAPL) and the possible biomass growth in the abiotic experiments. Approximately $8 \%$ of the TPH was reported to be volatilized to the $\mathrm{V}$ phase (low molecular weight diesel components) after 11 days, which is in agreement with other values found in the literature such as $5 \%$ of the naphthalene losses from control reactors for a period of $60 \mathrm{~h}$ (Wang and Vipulanandan, 2001). In addition, biomass growth may be considered negligible during the abiotic experiments.

The experimental data obtained under abiotic conditions were used to estimate mass transfer coefficients according to the steps previously described, and those coefficients are summarized in Table 1. Likewise, these experimental data have been used to validate the model with regard to the diesel distribution among phases, as previously shown in Figure 2.

In the literature, mass transfer models can be found for the description of the transport of organic pollutants: between river sediment to polyethylene passive samplers in the presence and absence of activated carbon (Hale and Werner, 2010); in flowing groundwater between mobile groundwater and stationary biofilms and diffusion within the biofilms (Mendoza-Sanchez and Cunningham, 2012); or between the water column and the sediment layer in a river (Wang et al., 2012). Likewise, Park et al. (2001) investigated the bioavailability of sorbed naphthalene in soil-slurry systems, and these authors obtained desorption rate coefficients from nonequilibrium sites of soils that ranged from 0.23 to $14.0 \mathrm{~h}^{-1}$, which agree with $\alpha$ value of 0.98 $\mathrm{h}^{-1}$ estimated for the desorption flux $\left(\mathrm{J}_{n}\right)$ by the present mathematical model. Similarly, Woo et al. (2001) studied the mass transfer coefficients for phenanthrene from the abiotic experimental data in soil-slurry systems for a roller-bottle test at $2 \mathrm{rpm}$, and these authors established that 
the overall mass transfer coefficient for phenanthrene sorbed in soil was $0.014 \mathrm{~h}^{-1}$ in a standard case of soil content. This last overall mass transfer coefficient value of $0.014 \mathrm{~h}^{-1}$ is quite similar to the $\mathrm{K}_{\mathrm{s}-\mathrm{A}}$ value of $0.03 \mathrm{~h}^{-1}$ estimated by the present mathematical model. However, no information is available on mass transfer coefficients among the 4 phases (solid, aqueous, NAPL, and gas) involved in a remediation technique for soil contaminated by TPH.

\subsection{Model validation and parameter estimation for bioremediation experiments}

Figure 4 shows the experimental data (points) of different bioremediation experiments and the model predictions (lines) for treatment of clayey soils artificially polluted with diesel hydrocarbons. In Figure 4, four pairs of figures ( $a, b, c, d)$ are plotted to represent the different bioremediation strategies used: (a) biostimulation, i.e., using the autochthonous microbial consortium, $\mathrm{X}_{0}$; (b) exogenous bioaugmentation, using sterile soil and the addition of an acclimated external consortium, $\mathrm{X}_{\mathrm{c}}$; (c) a combination of biostimulation with exogenous bioaugmentation, $\mathrm{X}_{0}+\mathrm{X}_{\mathrm{c}}$; and (d) a combination of biostimulation with bioaugmentation using the same autochthonous consortium previously enriched with diesel fuel for 4 weeks, $X_{0}+X_{0 e}$. More details about the different strategies were reported by Moliterni et al. (2012a). On the left, the figures show the time courses of total TPH concentration $\left(C_{T}\right)$ and the biomass evolution, whereas on the right, the figures show the diesel concentration through time in the phases of the soil-slurry system $\left(C_{A}, C_{\text {NAPL }}, C_{S}\right)$.

More than $60 \%$ of the diesel was observed to be biodegraded in all experiments in the first 48 h, and, regardless of bioremediation strategy used, more than $90 \%$ of the initial TPH was biodegraded after 11 days. The diesel was desorbed from the soil in the first experimental hours, and consequently, the diesel concentration increased in the NAPL phase. Subsequently, a decrease in the diesel concentration was observed in the NAPL phase between 30 and $70 \mathrm{~h}$ due to diesel biodegradation. In the NAPL phase, the first increase and later decrease in the diesel concentration were more or less significant depending on the bioremediation strategy used, and 
this scheme would support one of the model assumptions, because it has been supposed that strategy. This behaviour of diesel in the NAPL phase is the same as in the aqueous phase, although a higher diesel concentration in the aqueous phase exists at the first experimental time. The diesel concentration also decreased in the aqueous phase over time due to the biodegradation process, and this decrease was more significant for a combination of biostimulation and bioaugmentation strategies. The final amount of biomass growth was also reported to be very similar in all bioaugmentation strategies, although the lag time of adaptation for the polluted microcosms in each case is different. Likewise, biomass concentration increased over time, assuming that the consortia are well adapted to the microcosms, and a higher biomass concentration produces an increase in the diesel biodegradation rate. In general, the combined biostimulation/bioaugmentation strategies $\left(\mathrm{X}_{0}+\mathrm{X}_{\mathrm{C}}\right.$ and $\left.\mathrm{X}_{0}+\mathrm{X}_{0 \mathrm{e}}\right)$ lead the maximum diesel biodegradation efficiencies and rates compared to simple strategies $\left(\mathrm{X}_{0}\right.$ and $\mathrm{X}_{\mathrm{C}}$ ) (Moliterni et al., 2012a).

Once the experimental data were briefly explained, the results shown in Figure 4 were fitted to equations [2], [4], [5] and [7] to predict the behaviour of the bioremediation process in clayey soil-water suspensions. For fitting the model to the experimental data, it is necessary to estimate the model parameters $\mu_{\max }, K_{\mathrm{s}}$ and $Y_{\mathrm{X} / \mathrm{s}}$. The final values of these estimated parameters are shown in Table 2. On one hand, the highest values of the maximum specific growth rate $\left(\mu_{\max }\right)$ were obtained in the experiments carried out by the combination of biostimulation and bioaugmentation strategies $\left(\mathrm{X}_{0}+\mathrm{X}_{\mathrm{C}}\right.$ and $\left.\mathrm{X}_{0}+\mathrm{X}_{0 \mathrm{e}}\right)$, whereas the lowest values were observed for simple exogenous bioaugmentation $\left(X_{c}\right)$. Thus, the experiments with the combination of biostimulation and bioaugmentation strategies presented a maximum growth rate of approximately $0.01 \mathrm{~h}^{-1}$, which is one order of magnitude higher than in the experiments with simple exogenous bioaugmentation. On the other hand, the values obtained for the half saturation coefficient $\left(\mathrm{K}_{\mathrm{s}}\right)$ were in the range of 4162 to $9300 \mathrm{mg} \mathrm{Kg}_{\text {soil }}{ }^{-1}$, presenting the same 
order of magnitude whatever the strategy used. Finally, the values of the biomass yield coefficient $\left(Y_{x / s}\right)$ were observed to be slightly higher for the combination of biostimulation and bioaugmentation strategies.

Kinetic parameters $\left(\mu_{\max }, \mathrm{K}_{\mathrm{s}}, \mathrm{Y}_{\mathrm{x} / \mathrm{s}}\right)$ calculated in the present work are within the same order of magnitude as the values found in the literature. Thus, in the kinetic study of a diesel-degrading bacterium that was isolated from a diesel-contaminated site in Malaysia (Dahalan et al., 2014), the $\mu_{\max }$ rate had a value of $0.039 \mathrm{~h}^{-1}$, slightly higher compared to the $\mu_{\max }$ rate value of 0.0146 $\mathrm{h}^{-1}$ estimated by the present mathematical model for the combination of biostimulation with enriched autochthonous bioaugmentation $\left(\mathrm{X}_{0}+\mathrm{X}_{0 \mathrm{e}}\right)$. In general, the $\mu_{\max }$ rate values shown in Table 2 are also within the range found in the literature that varied between $0.036 \mathrm{~h}^{-1}$ for phenanthrene biodegradation and $0.468 \mathrm{~h}^{-1}$ for naphthalene biodegradation in soil (Mulder et al., 2001). Otherwise, $Y_{x / s}$ values in Table 2 are lower than those $Y_{x / s}$ values reported in the literature for microorganisms that can use the polycyclic aromatic hydrocarbons as source of energy, which range from 0.25 to $1.2 \mathrm{~kg} \mathrm{~kg}^{-1}$ (Mulder et al., 2001; Song et al., 2014).

In the literature, the bioremediation process of hydrocarbon-polluted soils has been separately modelled by mass transfer or kinetic models. Thus, some researchers have developed mass transfer models to describe, for instance, the mass transfer of hydrocarbons from the nonaqueous phase liquid to the aqueous phase (Mukherji et al., 1998) or from river sediment to activated carbon (Hale and Werner, 2010). Likewise, several kinetic models have been reported because the kinetics in the soil bioremediation processes are of great importance in understanding the hydrocarbon degradation rate and the efficiency. According to the literature (Yadav and Hassanizadeh, 2011), different simplified kinetic models could be used such as zeroorder kinetic, first-order or linear kinetic, the hyperbolic equation proposed by the Monod (Monod, 1949), logarithmic model or logistic model. The zero-order kinetic, logarithmic model and logistic model are not generally use to describe hydrocarbon biodegradation in soils, but 
the first-order kinetic model has been widely used due to the easier data analysis and simplicity current experimental data such as the i) biodegradation of a soil polluted with used engine oil (Abioye et al., 2010); ii) degradation of kerosene in soils by bioattenuation, biostimulation, bioaugmentation and combined biostimulation and bioaugmentation (Agarry et al., 2010); iii) biodegradation of diesel fuel in soil enhanced by the addition of tea leaf, soy cake and potato skin (Dadrasnia and Agamuthu, 2013); iv) bioremediation of a chronically oily sludge-polluted soil by natural attenuation, biostimulation and bioaugmentation (Soliman et al., 2014); v) biodegradation of phenanthrene and pyrene in soil-water systems (Yu et al., 2014); and vi) biodegradation of diesel oil in soils enhanced by bioventing as a biostimulation agent and amendment with organic waste effluents that could serve as a bioaugmentation agent (Agarry and Latinwo, 2015). At this point, the mentioned experimental data fitted well to the first-order kinetic model, with correlation coefficients higher than 0.90 . However, the most popular kinetics for characterizing hydrocarbon biodegradation is the Monod kinetics because it can describe degradation rates ranging from zero- to first-order kinetics with respect to the target pollutant concentration; thus, it seems to be the most rigorous of the simplified kinetic models mentioned. Hence, some researchers have used the Monod kinetic model to estimate both microbial growth and biodegradation of hydrocarbon pollutants in soils. Chen et al. (2008) considered the Monod model to fit biodegradation kinetics of phenanthrene in contaminated sediment slurry and Dahalan et al. (2014) studied the growth of a diesel-degrading bacterium isolated from a diesel-contaminated soil in Malaysia by using the Monod model. Nevertheless, these researchers did not obtain high correlation coefficients $\left(r^{2}\right)$ and for that reason, other researchers combined Monod and logistic kinetics to fit experimental data in the study of the natural attenuation of hydrocarbon contaminants as observed in a field lysimeter experiment, and they achieved an $\mathrm{r}^{2}$ value of 0.91 (Song et al., 2010). 
Furthermore, it is also possible to find models that couple mass transfer phenomena with kinetics to study the bioremediation process of hydrocarbon polluted groundwater in the literature. Thus, some researchers have developed models that couple the transport of hydrocarbons with Monod kinetics for hydrocarbon biodegradation in groundwater (MendozaSanchez and Cunningham, 2012; Song et al., 2014). Song et al. (2014) developed a mathematical model to simulate groundwater flow, naphthalene transport and biokinetic parameters that provides a general description of the experimental trends, although there are some discrepancies between the observed and simulated data. These discrepancies are that naphthalene pulses broke through earlier and the experimental naphthalene spread out wider in the experiment than predicted by the model and that the peak naphthalene breakthrough concentration data from experiments are almost all greater than that simulated by the model.

However, in the literature, there are few mathematical models that couple mass transfer phenomena with kinetics for hydrocarbon biodegradation in soils. At this point, Park et al. (2001) developed a mathematical model to fit experimental data from the degradation of naphthalene by using an exogenous bioaugmentation strategy in sandy soils from forest environments in Michigan. This model assumed that soils have equilibrium, nonequilibrium and non-desorption sites that can be accessed by biomass, and the model fitted both liquid and sorbed data reasonably with $r^{2}>0.988$ for Monod kinetics and $r^{2}>0.990$ for first-order kinetics used. Another mathematical model was found in the literature (Wang and Vipulanandan, 2001) to describe the degradation of $25,000 \mathrm{mg} / \mathrm{kg}$ of naphthalene using an exogenous bioaugmentation strategy in soil samples prepared by mixing various amounts of sand, clay and organic matter. Here, the model assumed that biodegradation occurs only in the aqueous phase following first-order kinetics, and then, researchers observed that their predictions were in agreement with experimental data although correlation coefficients were not evaluated. Likewise, Woo et al. (2001) proposed a mathematical model to describe the degradation of phenanthrene in soils by the same bioremediation strategy mentioned above. This model with sorbed-phase 
biodegradation and the same Monod kinetic parameters, but unique mass transfer coefficients, error. Kosterin and Sofinskaya (2010) developed a mathematical model for the $1 \mathrm{wt} \% \mathrm{n}$ tridecane degradation by using biostimulation strategy in an oil-polluted soil. This model includes equations for the diffusion transfer of hydrocarbons and microorganisms into the water phase and the Monod equation for the biodegradation process, and the model was expanded by the hypothesis that the hydrocarbon-oxidizing microorganisms, in the course of their life activity, excrete products whose specific concentrations inhibit the utilization of the hydrocarbon. Thus, this model fitted experimental data with deviations no higher than $5 \%$.

In this context, to the best of our knowledge, the mathematical model proposed by the authors is the first model that couples the mass transfer of TPH into four phases (A, S, NAPL and V) with the Monod equation for TPH biodegradation and that studies four different bioremediation strategies in soil-slurry systems. Thus, Table 3 displays Pearson correlation coefficients to validate the model. The Pearson correlation coefficient test is a statistical analysis to determine the fit between experimental and modelled data for every phase studied in the system. The Pearson correlation coefficients shown in Table 3 indicate that the linear relationship between the two sets of data has a high positive correlation as the values of Pearson are above 0.95 in most bioremediation strategies, which is indicative of the correct reproducibility of the model and this finding would validate the assumptions on which the model is based.

\section{Conclusions}

A correct fit between the model predictions and the experimental data was observed because the modelling curves captured the major trends for the diesel distribution in each phase, and high Pearson correlation coefficient values were obtained. This finding would validate the assumptions on which the model is based. When available, the mass transfer coefficients and the kinetic parameters were compared to other values reported in the literature. However, to 
the best of our knowledge, no similar models were found that couple the diesel hydrocarbon mass transfer among four phases and Monod kinetics to describe the bioremediation process.

\section{Acknowledgements}

This study was funded by project CTM2006-03314 of the Spanish Government National Plan for Research and by project PBI08-0206-7303 of the Castilla-La Mancha regional Government.

\section{References}

Abioye PO, Aziz AA, Agamuthu P. Enhanced Biodegradation of Used Engine Oil in Soil Amended with Organic Wastes. Water Air Soil Pollut 2010;209:173-179.

Agarry S, Latinwo GK. Biodegradation of diesel oil in soil and its enhancement by application of bioventing and amendment with brewery waste effluents as biostimulation-bioaugmentation agents. J Ecol Eng 2015;16: 82-91.

Agarry SE, Aremu MO, Aworanti OA. Kinetic Modelling and Half-Life Study on Bioremediation of Soil Co-Contaminated with Lubricating Motor Oil and Lead Using Different Bioremediation Strategies. Soil Sediment Contam 2013;22:800-816.

Agarry SE, Owabor CN, Yusuf RO. Studies on Biodegradation of Kerosene in Soil under Different Bioremediation Strategies. Bioremediation Journal 2010;14:135-141.

Alshafie M, Ghoshal S. Naphthalene biodegradation from non-aqueous-phase liquids in batch and column systems: comparison of biokinetic rate coefficient. Biotechnol Prog 2003;19:844852.

ASTM E method 1755-01, Standard Test Method for Ash in Biomass. ASTM International, West Conshohocken, Pennsylvania, USA; 1991.

Atlas R, Bartha R. Microbial Ecology: Fundamentals and Applications. 4th ed. Redwood City, CA: Benjamin/Cummings; 1998. 
Chen J, Wong MH, Wong YS, Tam NFY. Multi-factors on biodegradation kinetics of polycyclic aromatic hydrocarbons (PAHs) by Sphingomonas sp. a bacterial strain isolated from mangrove sediment. Mar Pollut Bull 2008;57:695-702.

Dadrasnia A, Agamuthu P. Dynamics of diesel fuel degradation in contaminated soil using organic wastes. Int J Environ Sci Technol 2013;10:769-778.

Dahalan FA, Yunus I, Johari WLW, Shukor MY, Halmi MIE, Shamaan NA, Syed MA. Growth kinetics of a diesel-degrading bacterial strain from petroleum-contaminated soil. J Environ Biol 2014;35:399-406.

EN method 14039, Characterization of waste. Determination of hydrocarbon content in the range of C10 to C40 by gas chromatography. Bruxelles: European Committee for Standardization; 2005.

Fan MY, Xie RJ, Qin G. Bioremediation of petroleum-contaminated soil by a combined system of biostimulation-bioaugmentation with yeast. Environ Technol 2014;35:391-399.

Gargouri B, Karray F, Mhiri N, Aloui F, Sayadi S. Bioremediation of petroleum hydrocarbonscontaminated soil by bacterial consortium isolated from an industrial wastewater treatment plant. J Chem Technol Biotechnol 2014;89:978-987.

Gentry TJ, Rensing C, Pepper IL. New approaches for bioaugmentation as a remediation technology. Crit Rev Environ Sci Technol 2004;34:447-494.

Ghoshal S, Luthy RG. Biodegradation Kinetics of Naphtalene in Nonaqueous Phase Liquid-Water Mixed Batch Systems: Comparison of Model Predictions and Experimental Results. Inc Biotechnol Bioeng 1998;57:356-366.

Guo L, Wagenet RJ, Jury WA. Adsorption effects on kinetics of aldicarb degradation: equilibrium model and application to incubation and transport experiments. Soil Sci Soc Am J 1999;63:16371644. 
Hale SE, Werner D. Modeling the Mass Transfer of Hydrophobic Organic Pollutants in Briefly and Continuously Mixed Sediment after Amendment with Activated Carbon. Environ Sci Technol 2010;44:3381-3387.

ISO method 9377-2, Water quality: determination of hydrocarbon oil index. Part 2: method using solvent extraction and gas chromatography. International Organization for Standardization, Geneva; 2000.

Johnson MA, Song $X$, Seagren EA. A quantitative framework for understanding complex interactions between competing interfacial processes and in situ biodegradation. Contam Hydrol 2013;146:16-36.

Juhasz AL, Aleer S, Adetutu EM. Predicting PAH bioremediation efficacy using bioaccessibility assessment tools: Validation of PAH biodegradation-bioaccessibility correlations. Int Biodeter Biodegr 2014;95:320-329.

Kosterin AV, Sofinskaya OA. Simulation of Tridecane Degradation under Different Soil Water Contents. Eurasian Soil Sci+ 2010;43:712-718.

Lin TC, Pan PT, Young CC, Chang JS, Chang TC, Cheng SS. Evaluation of the optimal strategy for ex situ bioremediation of diesel oil-contaminated soil. Environ Sci Pollut Res 2011;18:14871496.

Ma XK, Ding N, Peterson EC. Bioaugmentation of soil contaminated with high-level crude oil through inoculation with mixed cultures including Acremonium sp. Biodegradation 2015;26:259-269.

Mendoza-Sanchez I, Cunningham J. Efficient Algorithms for Modeling the Transport and Biodegradation of Chlorinated Ethenes in Groundwater. Transp Porous Med 2012;92:165-185. Moliterni E, Rodriguez L, Fernández FJ, Villaseñor J. Feasibility of Different Bioremediation Strategies for Treatment of Clayey and Silty Soils Recently Polluted with Diesel Hydrocarbons. Water Air Soil Pollut 2012a;223:2473-2482. 
Moliterni E, Jiménez-Tusset RG, Villar Rayo M, Rodríguez L, Fernández FJ, Villaseñor J. Kinetics of biodegradation of diesel fuel by enriched microbial consortia from polluted soils. Int J Environ Sci Technol 2012b;9:749-758.

Monod J, The growth of bacterial cultures. Annu Rev Microbiol 1949;3:371-394.

Mrozik A, Piotrowska-Seget Z. Bioaugmentation as a strategy for clearing up of soils contaminated with aromatic compounds. Microbiol Res 2010;165:363-375.

Mukherji S, Walter J, Weber Jr. Mass transfer effects on microbial uptake of naphthalene from complex NAPLs. Biotechnol Bioeng 1998;60:750-760.

Mulder $\mathrm{H}$, Breure AM, Rulkens WH. Application of a mechanistic desorption-biodegradation model to describe the behavior of polycyclic aromatic hydrocarbons in peat soil aggregates. Chemosphere 2001;42:285-299.

Nakahara T, Erickson LE, Gutierrez JR. Characteristics of hydrocarbon uptake in cultures with to liquid phases. Biotechnol Bioeng 1977;19:9-25.

Nasseri S, Rezaei Kalantary R, Nourieh N, Naddafi K, Mahvi AH, Baradaran N. Influence of bioaugmentation in biodegradation of PAHs-contaminated soil in bio-slurry phase reactor. Iran J Environ Health Sci Eng 2010;7:199-208.

Nocentini M, Pinelli D, Fava F. Bioremediation of a soil contaminated by hydrocarbon mixtures: the residual concentration problem. Chemosphere 2000;41:1115-1123.

Ostendorf DW, Schoendberg TH, Hinlein ES, Long SC. Monod kinetics for aerobic biodegradation of petroleum hydrocarbons in unsaturated soil microcosm. Environ Sci Technol 2007;41:23432349.

Park JH, Zhao X, Voice TC. Biodegradation of non-desorbable naphthalene in soils. Environ Sci Technol 2001;35:2734-2740.

Ramaswami A, Luthy RG. Mass transfer and bioavailability of PAH compounds in coal tar NAPLslurry systems. 1. Model development. Environ Sci Technol 1997;31:2260-2267. 
Rosenberg E, Rosenberg M, Shoham Y, Kaplan N, Sar N. Adhesion and desorption during the growth of Acinetobacter Calcoaceticus on hydrocarbons, ed by Cohen $\mathrm{Y}$ and Rosenberg $\mathrm{E}$. Microbial mats: Physiological ecology of benthic microbial communities, Washington DC; 1989. Soliman RM, El-Gendy NSh, Deriase SF, Farahat LA, Mohamed AS. The Evaluation of Different Bioremediation Processes for Egyptian Oily Sludge Polluted Soil on a Microcosm Level. Energ Source Part A 2014;36:231-241.

Song D, Kitamura M, Katayama A. Approach for Estimating MicrobialGrowth and Biodegradation ofHydrocarbon Contaminants inSubsoil Based on FieldMeasurements: 2. Application in a Field Lysimeter Experiment. Environ Sci Technol 2010;44:6795-6801.

Song $\mathrm{X}$, Hong $\mathrm{E}$, Seagren EA. Laboratory-scale in situ bioremediation in heterogeneous porous media: Biokinetics-limited scenario. J Contam Hydrol 2014;158:78-92.

Souza EC, Vessoni-Penna TC, Oliveira RP. Biosurfactant-enhanced hydrocarbon bioremediation: An overview. Int Biodeter Biodegr 2014;89:88-94.

Spasojevic JM, Maletic SP, Roncevic SD, Radnovic DV, Cucak DI, Trickovic JS, Dalmacija BD. Using chemical desorption of PAHs from sediment to model biodegradation during bioavailability assessment. J Hazard Mater 2015;283:60-69.

Suja F, Rahim F, Taha MR, Hambali N, Razali MR, Khalid A, Hamzah A. Effects of local microbial bioaugmentation and biostimulation on the bioremediation of total petroleum hydrocarbons (TPH) in crude oil contaminated soil based on laboratory and field observations. Int Biodeter Biodegr 2014;90:115-122.

Ueno A, Ito Y, Yumoto I, Okuyama H. Isolation and characterization of bacteria from soil contaminated with diesel oil and the possible use of these in autochthonous bioagmentation. World J Microbiol Biotechnol 2007;23:1739-1745.

Wang C, Feng Y, Zhao S, Li BL. A dynamic contaminant fate model of organic compound: A case study of Nitrobenzene pollution in Songhua River, China. Chemosphere 2012;88:69-76. 
Wang S, Vipulanandan C. Biodegradation of Naphthalene-contaminated soils slurry bioreactors. J Environ Eng 2001;127:748-754.

Woo SH, Park JM, Rittmann BE. Evaluation of the interaction between biodegradation and sorption of phenanthrene in soil slurry systems. Biotech Bioeng 2001;73:12-24.

Yadav BK, Hassanizadeh SM. An Overview of Biodegradation of LNAPLs in Coastal (Semi)-arid Environment. Water Air Soil Pollut 2011;220:225-239.

Youssef M, El-Taweel GE, El-Naggar AY, El-Hawary ShE, El-Meleigy MA, Ahmed SA. Hydrocarbon degrading bacteria as indicator of petroleum pollution in Ismailia Canal, Egypt. World Appl Sci J 2010;8:1226-1233.

Yu H, Huang GH, Xiao H, Wang L, Chen W. Combined effects of DOM and biosurfactant enhanced biodegradation of polycylicarmotic hydrocarbons (PAHs) in soil-water systems. Environ Sci Pollut Res 2014;21:10536-10549. 


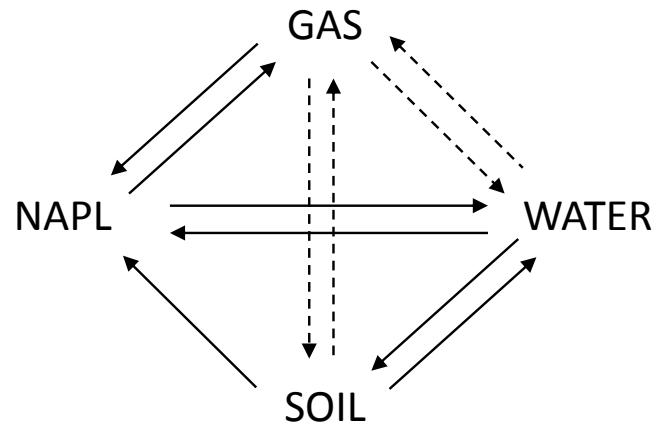

(a)

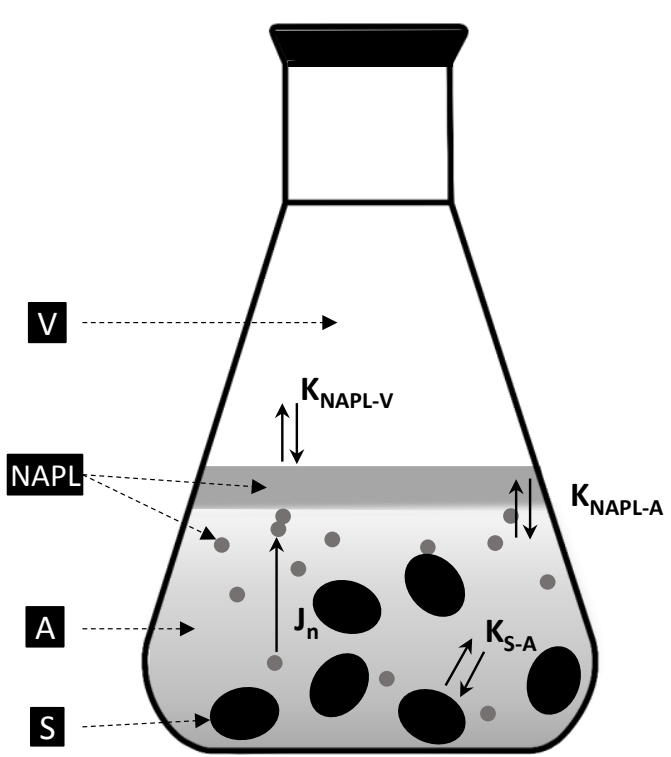

(b)

Figure 1. (a) Possible transport phenomena among phases (solid lines indicate mass transfer phenomena considered by the model and dotted lines indicate negligible mass transfer considered by the model). (b) Scheme of transport phenomena involved in the soil-slurry system. 
1

2

3

4

5

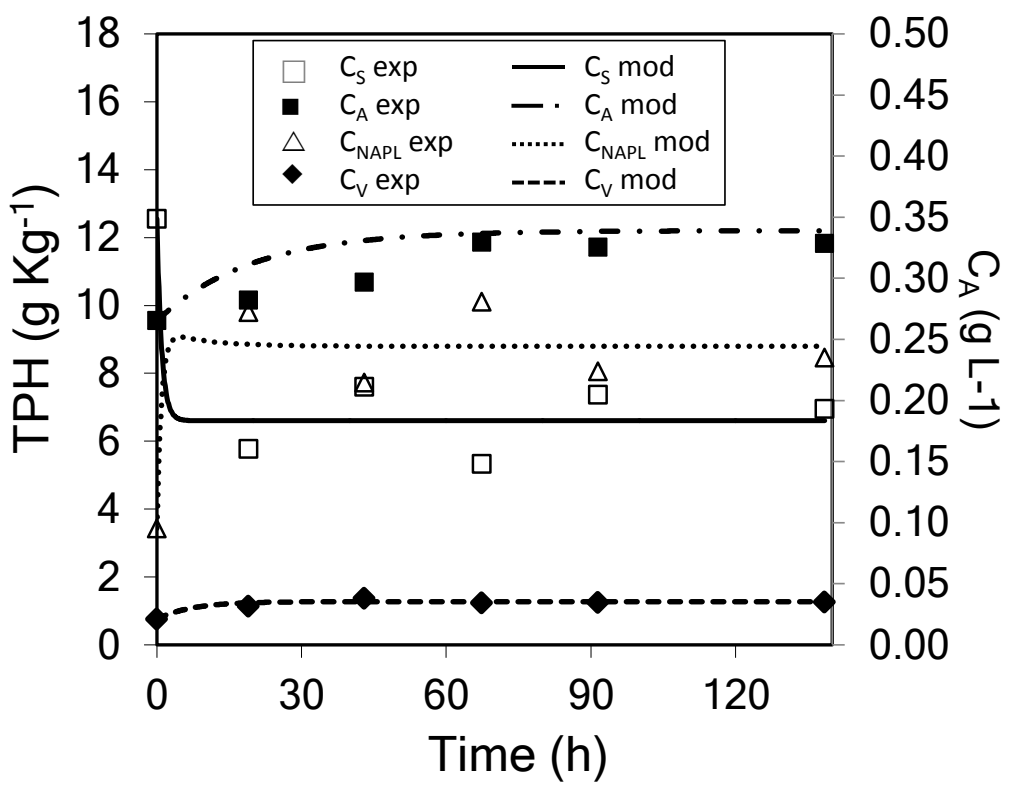

Figure 2. Diesel distribution in the abiotic experiments in soil-slurry systems. 
1

2

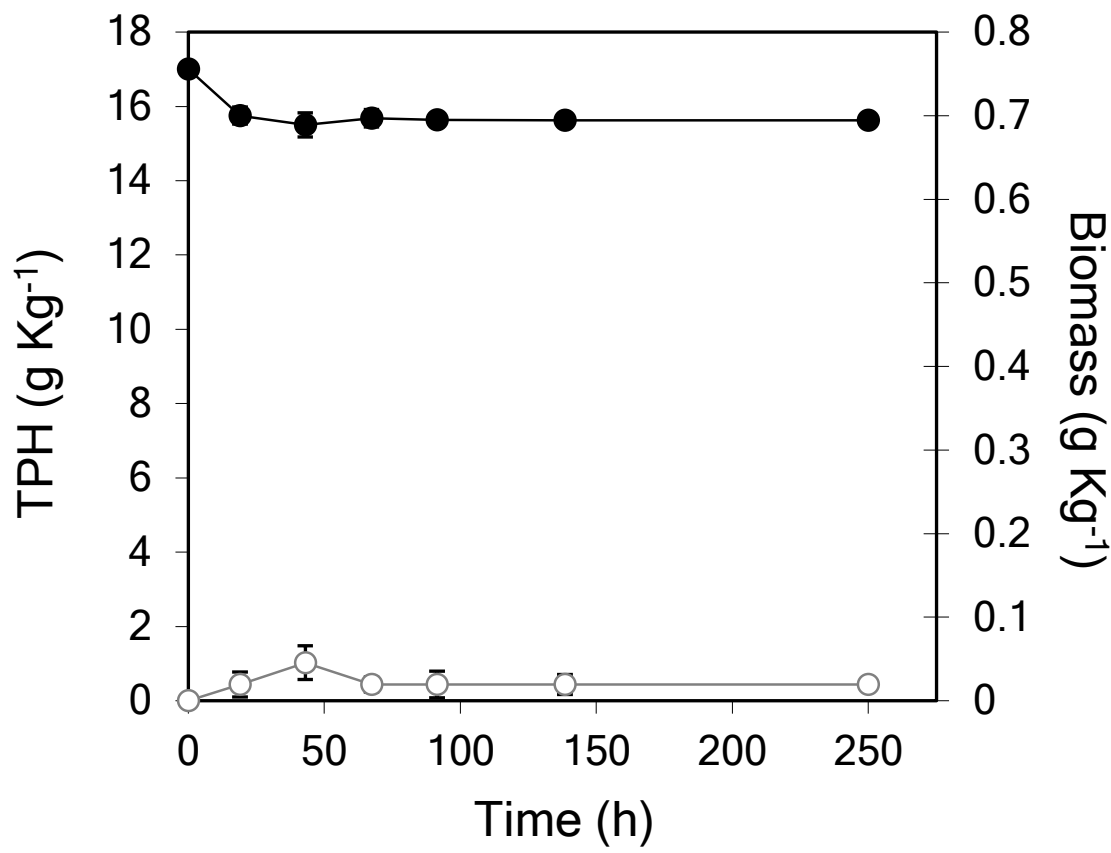

Figure 3. TPH and biomass concentrations in the abiotic experiments. (• TPH and $\circ$ biomass). TPH values include S, A and NAPL phases. Error bars represent the standard deviation of the mean, and lines represent tendencies. 
1
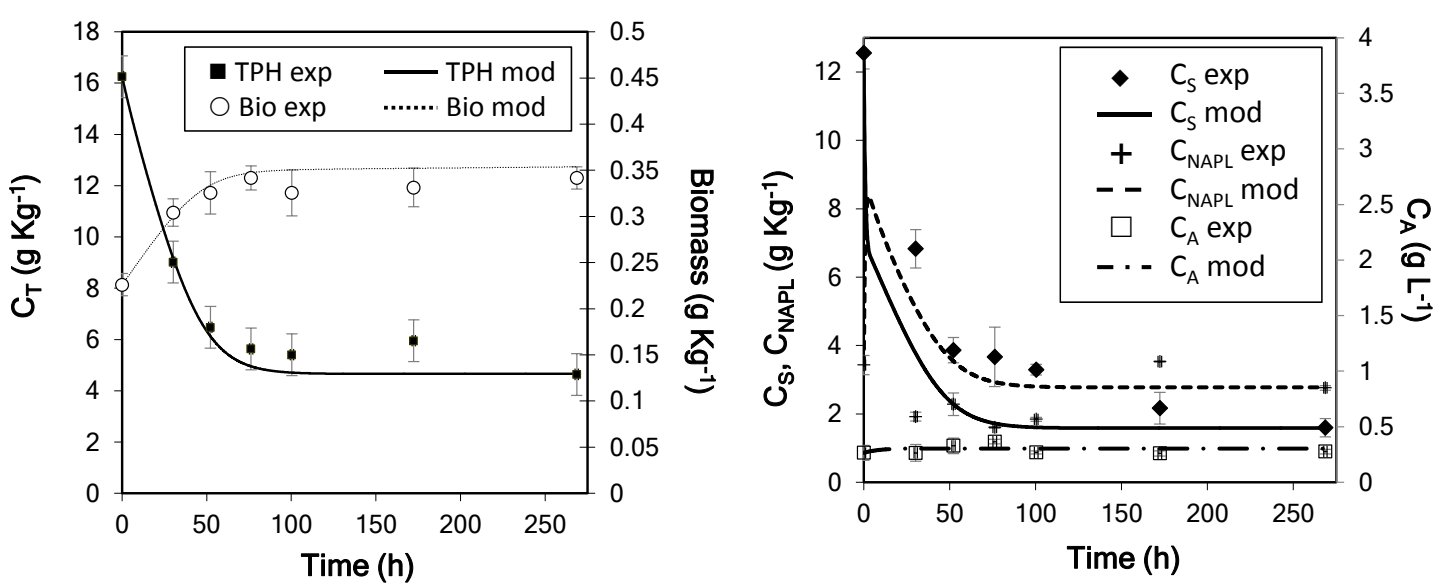

(a)
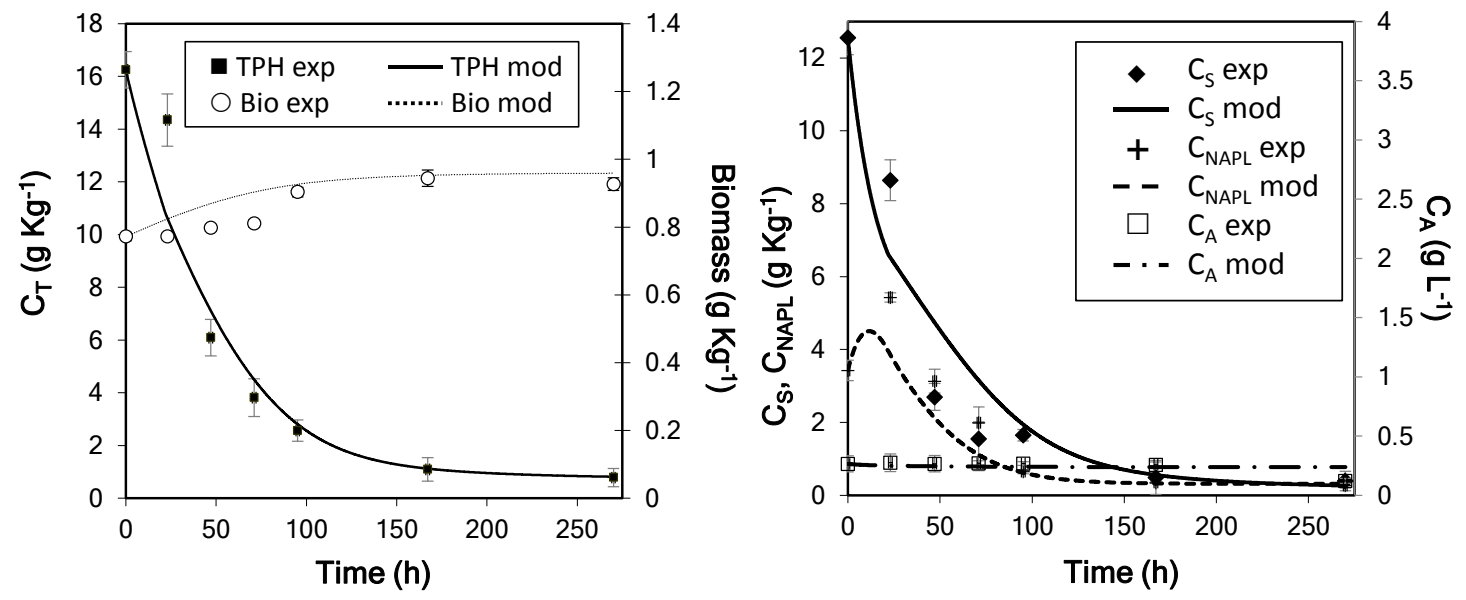

(b)
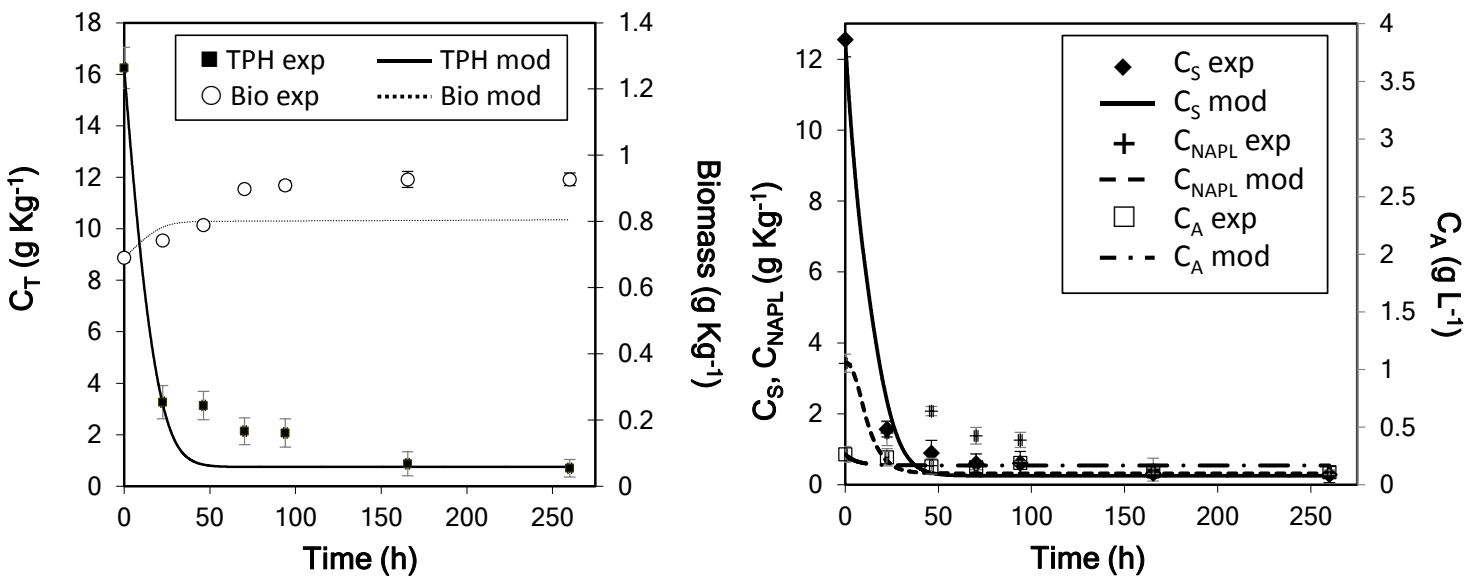

(c) 


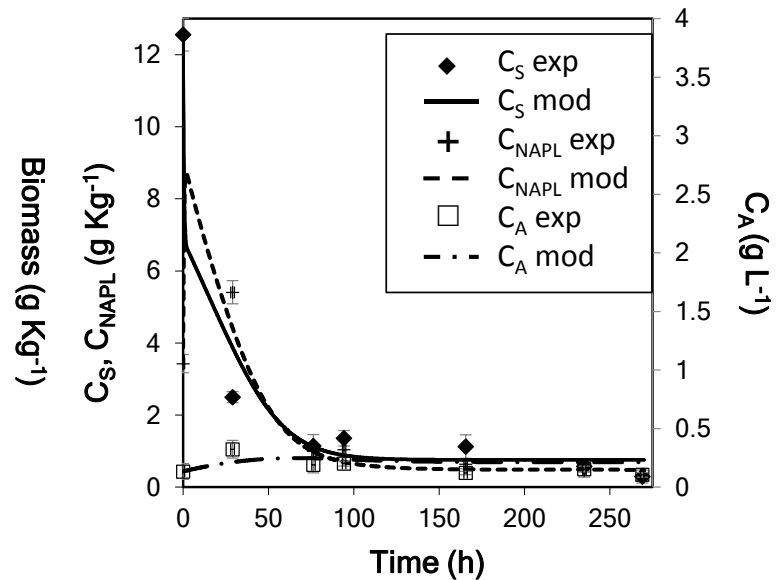

(d)

Figure 4. TPH and biomass concentrations in experiments with clayey soil. Experimental data (points) and model predictions (lines). Four strategies used: (a) biostimulation; (b) bioaugmentation; (c) combined biostimulation and exogenous bioaugmentation; and (d) combined biostimulation and autochthonous bioaugmentation. 
Table 1. Estimated parameters for the abiotic experiments.

1

2

3

4

5

6

7

8

9

10

11

12

13

14

15

16

17

18

19

20

21

22

23

24

25

26

27

28

29

30

31

32

33

34

35

36

37

38

39

40

41

42

43

44

45

46

47

48

49

50

51

52

53

54

55

56

57

58

59

60

61

62

63

64

65

\begin{tabular}{cccc}
\hline$K_{S-A}\left(\mathrm{~h}^{-1}\right)$ & $K_{\text {Napl-A }}\left(\mathrm{h}^{-1}\right)$ & $K_{\text {Napl-V }}\left(\mathrm{h}^{-1}\right)$ & $\alpha\left(\mathrm{h}^{-1}\right)$ \\
\hline 0.03 & 0.02 & 0.14 & 0.98 \\
\hline
\end{tabular}


1

Table 2. Estimated parameters for the bioremediation model.

\begin{tabular}{cccc}
\hline Strategy & $\begin{array}{l}\mu_{\max } \\
\left(\mathrm{h}^{-1}\right)\end{array}$ & $\begin{array}{c}K_{S} \\
\left(\mathrm{mg} \mathrm{Kg}_{\text {soil }}{ }^{-1}\right)\end{array}$ & $\begin{array}{c}Y_{\mathrm{X} / \mathrm{S}} \\
\left(\mathrm{mg}_{\text {cell }} \mathrm{mg}_{\mathrm{TPH}^{-1}}\right)\end{array}$ \\
\hline $\mathrm{X}_{0}$ & 0.0096 & 4162.4 & 0.011 \\
\hline $\mathrm{X}_{\mathrm{C}}$ & 0.0031 & 5898.5 & 0.010 \\
\hline $\mathrm{X}_{0}+\mathrm{X}_{\mathrm{C}}$ & 0.0114 & 5678.0 & 0.013 \\
\hline $\mathrm{X}_{0}+\mathrm{X}_{0 \mathrm{e}}$ & 0.0146 & 9300.0 & 0.031 \\
\hline
\end{tabular}


1

Table 3. Pearson correlation coefficients for the bioremediation model.

\begin{tabular}{cc}
\hline Strategy & Pearson Coefficient \\
\hline$X_{0}$ & 0.9234 \\
\hline$X_{c}$ & 0.9589 \\
\hline$X_{0}+X_{c}$ & 0.9688 \\
\hline$X_{0}+X_{0 e}$ & 0.9665 \\
\hline
\end{tabular}

